(C)1983. The Genetical Society of Great Britain

\title{
THE GENETIC CONTROL OF COPPER TOLERANCE IN THE YELLOW MONKEY FLOWER, MIMULUS GUTTATUS
}

\author{
M. R. MACNAIR \\ Department of Biological Sciences, University of Exeter, Washington Singer \\ Laboratories, Perry Road, Exeter, EX4 4QG, U.K.
}

Received 11.x.82

\section{SUMMARY}

Evidence is presented that copper tolerance in the yellow monkey flower, Mimulus guttatus is determined primarily by a single major gene. Selfed progenies of segregating $\mathrm{T} \times \mathrm{T}$ families produce families which are all $\mathrm{T}$, segregating or all NT in a $1: 2: 1$ ratio. Segregating $\mathrm{T} \times \mathrm{NT}$ crosses produce approximately 1:1 ratios. Significant heterogeneity between families within classes suggests that there are genetic modifiers also segregating, though some of the heterogeneity may be due to environmental factors. These results indicate that copper tolerance in this organism has evolved in a manner analogous to other adaptations such as mimicry, industrial melanism and pesticide resistance. The results also suggest that physiological models of metal tolerance involving many biochemical and physiological changes may need revision.

\section{INTRODUCTION}

Heavy metal tolerance in higher plants is one of the best studied examples of local adaptation or small-scale evolution (see Macnair, 1981, for a recent review). We have, however, an imperfect understanding of the basic genetic control of this phenomenon. In particular, it is not clear whether this adaptation is generally produced by the combined action of several or many genes, individually of small effect (polygenic control) or whether there is normally one or a small number of major genes responsible for the bulk of the tolerance manifested in any individual. Genetic studies on Festuca ovina (Wilkins, 1960; Urquhart, 1971), Agrostis tenuis (Gartside and McNeilly, 1974c), Anthoxanthum odoratum (Gartside and McNeilly, 1974a) and Silene inflata (Bröker, 1963) have all been interpreted as indicating polygenic control, or at least that a simple major gene system is not involved.

Macnair (1977), on the other hand, suggested that in the yellow monkey flower, Mimulus guttatus, copper tolerance appeared to be governed by two major genes. This conclusion was based on the observation that backcrosses segregated into tolerants and non-tolerants at high levels of copper, and that in these backcrosses the ratio tolerant: non-tolerant was $1: 3$. While distinct segregation into easily interpreted ratios can obviously be explained in terms of major genes, such evidence does not rule out a polygenic model entirely. It might well be possible to construct a model involving underlying polygenic control which could give similar ratios in the first backcrosses. In subsequent generations however, the predictions of the two models will diverge. In particular any polygenic model would predict that some crosses between non-tolerants should yield a proportion 
of tolerants, while under a major gene model only certain sorts of interaction will produce this result.

In this paper and the accompanying one (Macnair and Christie, 1983) we report on further crosses that clarify the genetic control of this character in $M$. guttatus. Here I show that tolerance to high levels of copper is produced by the action of a single gene or supergene; in the accompanying paper we show that this gene is associated with a synthetic lethal system producing partial postmating reproductive isolation.

\section{MAterials AND METHOdS}

\section{(i) Mimulus guttatus}

$M$. guttatus is a useful organism for genetical analysis (Allen and Sheppard, 1971). Its sensitive stigma makes emasculation easy, and generally the stigma will not reopen if there is any pollen on it. However, a proportion of illicit progeny have been found in a few crosses, particularly when the male parent is of low fertility. It is selfcompatible, and a single cross can produce between 50 and 1500 seeds, depending on female parent, and there is no seed dormancy. A generation can be completed in less than 100 days.

\section{(ii) Provenance of the wild parents}

The crosses reported here are derived from three individuals from wild populations:

(a) C10: a typical tolerant individual from the Copperopolis population studied by Allen and Sheppard (1971);

(b) Cer 34: an individual from a British population at Cerig-y-drudion, N. Wales, also described in Allen and Sheppard (1971);

(c) SB8: an individual collected from a large non-tolerant population growing in a roadside ditch about $2 \mathrm{~km}$ south-east of the town of Stinson Beach, Marin County, California.

\section{(iii) Tolerance testing}

Plants were categorized as tolerants (T) or non-tolerants (NT) as previously (Macnair, 1977), on the basis of whether or not they formed proper roots in a $0.5 \mathrm{ppm}$ copper solution. Previously, individuals had been tested with replication, but in the crosses reported here families were grown in seed trays, so that individuals generally produced only a single stem and replication was rarely possible. In most cases 60 seedlings were pricked out into $35 \mathrm{~cm} \times 23 \mathrm{~cm}$ trays, but some later families had only 30 seedlings in $17.5 \mathrm{~cm} \times 23 \mathrm{~cm}$ trays. Seedling mortality in most trays was low. Families within a sowing were randomized, and tested when all individuals had attained a height of at least $8 \mathrm{~cm}$. Trays were harvested, and all individuals from the tray tested simultaneously by rooting the cuttings in $0.5 \mathrm{ppm} \mathrm{Cu}$ in $0.5 \mathrm{gl}^{-1}$ calcium nitrate in deionized water. Testing conditions were the same as previously (Macnair, 1977, 1979). After a week in solution, the longest root of each tolerant individual was measured. Plants which produced short $(0-2 \mathrm{~mm})$ stubby root initials which had gone brown were 
classified as non-tolerants. Individuals producing no roots at all were not classified and wherever possible grown on in $3^{\prime \prime}$ pots and retested. Up to 4 cuttings of plants being retested were rooted at $0.5 \mathrm{ppm}$ copper.

\section{(iv) The validity of the testing procedure}

Some measure of the reliability and repeatability of this testing procedure is required. Because the tolerance test depends on the ability to distinguish plants which have formed good roots from those growing short stumpy ones, it is clear that most (probably all) mis-scoring is going to be in the direction $\mathrm{T} \rightarrow \mathrm{NT}$. There are two independent indicators that the rate of mis-scoring is rather low:

(a) In the series of crosses reported here and others, there are a large number of plants which have been tested with replicate cuttings. In total there are 1204 such plants: 612 tested consistently as tolerants, 561 as non-tolerants, and there were 31 for which the replicates disagreed. If we assume that all 31 were really tolerant, then this gives an estimate of mis-scoring tolerants of 2.5 per cent.

(b) There is the evidence of progeny testing. Four plants classified as NT produced progeny that can be best explained by assuming that the plant was really tolerant. None of 99 different $T$ plants used as parents proved to be really NT. Thus this gives an estimate of mis-scoring of 4 per cent.

Notwithstanding this evidence that the rate of mis-scoring is generally low, it became evident that in a few families the rate could be much higher. Some families, for reasons which are largely obscure, tested badly, in that many individuals were unclassifiable because they produced no roots, and others produced short roots and their classification was doubtful. In one extreme example, a family which was predicted to have no NTs produced 13 ; all proved to be really tolerant on retesting. In the majority of families however, the testing went well, and classification was clear (see Macnair, 1981, fig. 6.1).

\section{(v) Crossing programme}

The tolerant F1 of the cross between $\mathrm{C} 10$ and Cer 34 was backcrossed to Cer 34 . From this backcross family 4 tolerant and 5 non-tolerant individuals were selected:

$$
\begin{array}{ll}
\text { Tolerants: } & 5556 / 54,5556 / 57,5556 / 62,5556 / 64 \\
\text { Non-tolerants: } & 5556 / 74,5556 / 56,5556 / 69,5556 / 60,5556 / 13
\end{array}
$$

These plants were intercrossed in various ways. The resulting families are described for convenience as the Gen 1 series of families. Progeny from various of these crosses were then further intercrossed to give the Gen 2 series.

The progeny of two segregating $\mathrm{T} \times \mathrm{T}$ crosses (families 5600 and 5587) were grown on after testing. All male fertile individuals were selfed, and all tolerant individuals were crossed to SB8. The provenance of the two 
families was:

$$
\begin{array}{ll}
5587: & 5556 / 57 \times 5556 / 64 \\
5600: & (5556 / 57 \times 5556 / 74) \times(5556 / 57 \times 5556 / 62)
\end{array}
$$

\section{Results}

(a) Evidence for a single major gene for tolerance:

(i) $N T \times N T$ crosses:

Twenty-one NT $\times$ NT families from the Gen 1 and Gen 2 series were grown, a total of 876 individuals, all of which were non-tolerant. This result is difficult to accommodate within a polygenic model, since if tolerance at $0.5 \mathrm{ppm}$ were simply the end of a continuous distribution, one would have expected a proportion of the progeny of some families to have shown tolerance.

\section{(ii) Analysis of 5600 and 5587 families:}

Forty-five of the fifty 5600 plants tested survived to flowering and were selfed. Two proved to be male sterile; one, $5600 / 30$, which was tolerant, was crossed to SB8; the other, $5600 / 24$, which had been scored as a non-tolerant, was crossed to another non-tolerant, 5600/55. These two crosses, plus all the other selfs, were grown up and tested. Thirty-nine plants from 5587 were grown on and selfed. Both sets of families consisted of families of three types: all tolerant, all non-tolerant, or segregating (see table 1). All families producing only non-tolerants had parents which were

TABLE 1

Number of progenies produced by selfing individuals from families 5600 and 5587 falling into each of the three segregation classes

\begin{tabular}{ccccc}
\hline Series & All T & Segregating & All NT & \multicolumn{1}{c}{$\chi^{2 *}$} \\
\hline 5600 & 12 & 26 & 7 & $2 \cdot 2 \mathrm{NS}$ \\
5587 & $\frac{7}{19}$ & $\frac{21}{47}$ & $\frac{11}{18}$ & $1.05 \mathrm{NS}$ \\
& 19 & & $1.21 \mathrm{NS}$
\end{tabular}

Heterogeneity $\chi_{2}^{2}$ between series: $2 \cdot 32$ NS

${ }^{*} \chi^{2}$ test for deviation from $1: 2: 1$ ratio.

non-tolerant; also all tolerant individuals produced either segregating or all T families. However, two 5600 NTs (one of them 5600/24) produced all $\mathrm{T}$ families, and one $5587 \mathrm{NT}$ produced a segregating family. These three plants were probably mis-scored in the first instance. One 5587 family from an NT parent produced a bizarre ratio which on progeny testing proved to have been due to an illegitimate cross (see below); this family has been included amongst the all NT families.

Both series produce the three family types in the $1: 2: 1$ ratio predicted if tolerance was governed by a single major gene. However, in both series the segregating families show evidence of heterogeneity of $T: N T$ ratio (see 
TABLE 2

Ratios obtained in segregating families produced by selfing individuals from family 5600

\begin{tabular}{|c|c|c|c|}
\hline \multirow[b]{2}{*}{ Family } & \multirow{2}{*}{$\begin{array}{c}5600 \\
\text { Parent }\end{array}$} & \multicolumn{2}{|c|}{ Progeny } \\
\hline & & $T$ & NT \\
\hline 5701 & 1 & 55 & 28 \\
\hline 5702 & 2 & 37 & 20 \\
\hline 5704 & 4 & 37 & 12 \\
\hline 5708 & 8 & 41 & 18 \\
\hline 5710 & 10 & 33 & 27 \\
\hline 5712 & 15 & 35 & 25 \\
\hline 5715 & 19 & 43 & 16 \\
\hline 5717 & 21 & 37 & 22 \\
\hline 5720 & 27 & 44 & 10 \\
\hline 5723 & 31 & 38 & 20 \\
\hline 5724 & 32 & 28 & 16 \\
\hline 5726 & 34 & 38 & 21 \\
\hline 5728 & 36 & 39 & 19 \\
\hline 5729 & 37 & 19 & 24 \\
\hline 5730 & 38 & 38 & 13 \\
\hline 5731 & 40 & 36 & 19 \\
\hline 5732 & 42 & 24 & 36 \\
\hline 5733 & 44 & \multicolumn{2}{|c|}{ Segregating } \\
\hline 5734 & 45 & 40 & 16 \\
\hline 5735 & 46 & 26 & 33 \\
\hline 5736 & 48 & 46 & 13 \\
\hline 5737 & 49 & 50 & 17 \\
\hline 5739 & 51 & 10 & 4 \\
\hline 5741 & 54 & 46 & 13 \\
\hline 5745 & 58 & 46 & 12 \\
\hline \multirow[t]{2}{*}{5746} & 59 & 52 & 4 \\
\hline & & $\overline{938}$ & $\overline{458}$ \\
\hline
\end{tabular}

Heterogeneity $\chi_{24}^{2}=90 \cdot 10, p<0 \cdot 001$.

tables 2 and 3). In 5600 the heterogeneity $\chi^{2}$ is highly significant, while in 5587 it borders on formal significance, if only families with 60 plants pricked out are included.

(iii) Analysis of the progeny of 5587/21:

One of the non-tolerant progeny of $5587,5587 / 21$, produced on selfing a family that segregated $13 \mathrm{~T}: 43 \mathrm{NT}$. A sample of this family was grown on and crossed in various ways to investigate the cause of this ratio. All the selfs of tolerants segregated in a 3T:1NT ratio; all the selfs of NTs gave all NTs; and all the T $\times$ NT crosses gave a 1:1 ratio. This set of families is consistent with the one gene model, assuming that the original plant, 5587/21, was illegitimately crossed with a mixture of $T$ and NT pollen.

(iv) $T \times N T$ crosses:

In the Gen 2 series, $15 \mathrm{~T} \times \mathrm{NT}$ crosses were performed. All segregated, and the combined ratio of the 15 families is $400 \mathrm{~T}: 405 \mathrm{NT}$. However the 
TABLE 3

Ratios obtained in segregating families produced by selfing individuals from family 5587

\begin{tabular}{|c|c|c|c|}
\hline \multirow[b]{2}{*}{ Family } & \multirow{2}{*}{$\begin{array}{l}5587 \\
\text { Parent }\end{array}$} & \multicolumn{2}{|c|}{ Progeny } \\
\hline & & $T$ & NT \\
\hline 5754 & 7 & 36 & 22 \\
\hline 5758 & 23 & 32 & 14 \\
\hline 5760 & 20 & 33 & 20 \\
\hline 5761 & 19 & 46 & 11 \\
\hline 5763 & 17 & 37 & 13 \\
\hline 5764 & 16 & 44 & 15 \\
\hline 5765 & 15 & 43 & 16 \\
\hline 5769 & 11 & 33 & 22 \\
\hline 5770 & 9 & 33 & 21 \\
\hline 5771 & 8 & 31 & 14 \\
\hline 5772 & 6 & 38 & 15 \\
\hline 5773 & 4 & 40 & 18 \\
\hline 5775 & 2 & 31 & 23 \\
\hline 5776 & 1 & 27 & 27 \\
\hline 5780 & 29 & 17 & 12 \\
\hline 5781 & 31 & 22 & 7 \\
\hline 5783 & 33 & 16 & 8 \\
\hline 5785 & 35 & 19 & 11 \\
\hline 5786 & 36 & 21 & 5 \\
\hline 5787 & 55 & 18 & 6 \\
\hline \multirow[t]{2}{*}{5792} & 60 & 21 & 7 \\
\hline & & $\overline{638}$ & $\overline{307}$ \\
\hline
\end{tabular}

Heterogeneity $\chi_{2}^{2}$ for all families: $\chi_{20}^{2}=27 \cdot 77 \mathrm{NS}$

Heterogeneity $\chi^{2}$ excluding families grown 30 to a tray: $X_{13}^{2}=21.67, P=0.06$

heterogeneity between the 15 families is formally significant $\left(\chi_{14}^{2}=26 \cdot 11\right.$, $p=0.025$ ), so some caution is needed in interpreting this ratio.

Some crosses between tolerant members of the 5600 and 5587 families and the non-tolerant plant SB8 were grown up. These crosses behave as predicted if the one gene model is correct: all crosses to individuals which produce non-segregating families on selfing produce families which are all tolerant; while crosses to individuals which segregate on selfing themselves segregate with generally an approximately $1: 1$ ratio (see table 4 ), though the overall ratio is significantly different from $1: 1$.

(b) Cause of heterogeneity in segregating families:

In several of the series of crosses producing segregating families, significant heterogeneity for $\mathrm{T}$ : NT ratio has been found. There are several possibly causes of this, all or any of which may operate in some families to lead to the observed heterogeneity.

Some heterogeneity is possibly caused by illegitimate crosses or contamination by foreign seed. However, this is unlikely to be a major source since, apart from the family from $5587 / 21$ already discussed, only 3 possible contaminants have been found in all the progenies of NT $\times$ NT plants grown up, which are the only families in which this source of error can be detected. 
TABLE 4

Segregations obtained in crosses between SB8 and 5600 and 5587 individuals which segregated on selfing

\begin{tabular}{ccccc}
\hline Family & $\begin{array}{c}\text { Tolerant } \\
\text { parent }\end{array}$ & $\begin{array}{c}\text { Selfed } \\
\text { ratio }\end{array}$ & T & NT \\
\hline 5814 & $5587 / 19$ & $5 \cdot 83$ & 24 & 32 \\
5815 & $5587 / 17$ & $2 \cdot 85$ & 34 & 33 \\
5816 & $5587 / 11$ & $1 \cdot 50$ & 28 & 29 \\
5817 & $5587 / 16$ & $2 \cdot 93$ & 33 & 19 \\
5818 & $5587 / 15$ & $2 \cdot 69$ & 30 & 28 \\
5827 & $5587 / 20$ & $1 \cdot 65$ & 26 & 25 \\
5800 & $5600 / 04$ & $3 \cdot 08$ & 18 & 35 \\
5801 & $5600 / 58$ & $3 \cdot 83$ & 23 & 26 \\
5802 & $5600 / 54$ & $3 \cdot 54$ & 26 & 28 \\
5803 & $5600 / 48$ & $3 \cdot 54$ & 26 & 30 \\
5804 & $5600 / 46$ & $0 \cdot 79$ & 28 & 29 \\
5805 & $5600 / 42$ & $5 \cdot 88^{*}$ & 26 & 32 \\
5806 & $5600 / 37$ & $1 \cdot 76^{*}$ & 33 & 18 \\
5807 & $5600 / 34$ & $1 \cdot 81$ & 8 & 5 \\
5808 & $5600 / 32$ & $1 \cdot 75$ & 53 & 48 \\
5809 & $5600 / 10$ & $1 \cdot 22$ & 11 & 10 \\
5810 & $5600 / 15$ & $1 \cdot 40$ & 24 & 30 \\
5811 & $5600 / 21$ & $1 \cdot 68$ & 21 & 26 \\
5812 & $5600 / 27$ & $4 \cdot 40$ & 18 & 32 \\
5824 & $5600 / 40$ & $1 \cdot 75$ & 24 & 32 \\
5709 & $5600 / 08$ & $2 \cdot 28$ & 22 & 38 \\
5748 & $5600 / 01$ & $2 \cdot 6$ & 22 & 38 \\
5749 & $5600 / 02$ & $1 \cdot 85$ & 33 & 27 \\
5750 & $5600 / 51$ & seg & 31 & 26 \\
5753 & $5600 / 59$ & $13 \cdot 00$ & 22 & 30 \\
& & & 644 & 706 \\
Heterogeneity & $\chi_{24}^{2}=31 \cdot 35 \mathrm{NS}$ & & & \\
& & & &
\end{tabular}

* Ratio obtained on repetition of test.

Some heterogeneity could also be due to variations in the environment in which families were grown or tested. It has already been noted (see Materials and Methods) that some families tested badly, and produced many individuals whose phenotype was doubtful. Some evidence for this is given by two 5600 families which gave extremely low T: NT ratio (families 5732 and 5735). These families were repeated in full, and both proved much less extreme the second time: 5732 gave $47 \mathrm{~T}: 8 \mathrm{NT}$, and 5735 gave $30 \mathrm{~T}: 17 \mathrm{NT}$. The between scorings heterogeneity $\chi_{1}^{2}=25 \cdot 2, p<0 \cdot 001$.

Some of the heterogeneity is undoubtedly due to genetic variation as well. Evidence for this comes from two sources:

\section{(i) Gen 1 series, $T \times T$ crosses:}

The four tolerant plants from the original backcross were crossed in a half diallel design. The 10 resulting families were significantly heterogeneous (table 5). This heterogeneity is associated with the crosses involving the parents $5556 / 54$ and 5556/57. If the three crosses $54 \times 54$, $54 \times 57$ and $57 \times 57$ are considered separately from the other seven crosses, it can be seen (table 5) that both the within-group heterogeneities are 
TABLE 5

Segregation in crosses between the plants $5556 / 54,5556 / 57,5556 / 62$ and $5556 / 64$

\begin{tabular}{cccc}
\hline Family & Cross & T & NT \\
\hline 5588 & $57 \times 57$ & 37 & 34 \\
5640 & $54 \times 57$ & 28 & 25 \\
5575 & $54 \times 54$ & 47 & 30 \\
5587 & $57 \times 64$ & 55 & 22 \\
5578 & $54 \times 64$ & 43 & 23 \\
5586 & $64 \times 64$ & 52 & 17 \\
5569 & $57 \times 62$ & 58 & 15 \\
5639 & $62 \times 54$ & 43 & 10 \\
5570 & $62 \times 64$ & 60 & 13 \\
5564 & $62 \times 62$ & 44 & $\frac{17}{206}$
\end{tabular}

Heterogeneity $\chi_{9}^{2}=33.98, p<0 \cdot 001$

\begin{tabular}{lrrrr}
\hline \multicolumn{1}{c}{ Analysis of $\chi^{2}:$} & $\chi^{2}$ & df & $P$ \\
\hline Heterogeneity within families involving & & & \\
$\quad$ only parents 54 and 57: & $1 \cdot 67$ & 2 & NS \\
Heterogeneity within other seven families: & $7 \cdot 10$ & 6 & NS \\
Difference between two groups & $25 \cdot 21$ & 1 & $*$ \\
\hline
\end{tabular}

${ }^{*} P<0.001$.

non-significant, but the between-group $\chi^{2}$ is highly significant. The combined ratio for the families involving only 54 and 57 is $112 \mathrm{~T}: 89 \mathrm{NT}$ while that for the other 7 families is $355 \mathrm{~T}: 117 \mathrm{NT}$ (which is not significantly different from $3: 1$ ).

\section{(ii) Crosses between 5600 plants and SB8:}

If all the difference between 5600 families is due to environmental factors, then there should be no difference between the families produced by crossing the 5600 individuals to a common non-tolerant (SB8). To test this, two groups of SB8 crosses were grown up: those with 5600 parents producing selfed ratios at the lower end of the range ( $\mathrm{T}: \mathrm{NT}$ ratios between 1 and 2 ) and those where the selfed ratios were higher ( $T: N T$ ratio $>2$ ). The $T$ : NT ratios in the crosses to SB8 are homogeneous within each group (low ratio group, heterogeneity $\chi_{7}^{2}=3 \cdot 89 \mathrm{NS}$, high ratio group $\chi_{8}^{2}=5 \cdot 43 \mathrm{NS}$ ) but there is evidence of heterogeneity between the two groups. The low ratio plants produce a pooled $\mathrm{T}: \mathrm{NT}$ ratio of $202: 207$, while the corresponding ratio from the high ratio plants is $203: 289$. These differ significantly $\left(\chi^{2}=5.96, P=0.015\right)$. This effect is rather puzzling, since it is the plants which produce a high ratio on selfing that produce the low ratio when crossed to SB8, and it is being investigated further. This phenomenon does not seem to pertain in the 5587 families.

Thus there is evidence that some of the heterogeneity in $T: N T$ ratio between families may be caused by the segregation of other genes that modify the expected ratios in segregating families. Whether these gene(s) act by reducing penetrance (i.e., by increasing the risk of mis-scoring 
tolerants for non-tolerants) or by reducing actual physiological tolerance is not yet clear.

Finally, two caveats must be made. The data indicate that a single gene is involved in producing tolerance at $0.5 \mathrm{ppm}$. Strictly speaking, we are considering a single segregational unit, and it is possible that there are two or more very closely linked loci behaving as a supergene. We have no evidence on this point. We do know that associated with the gene described here is a gene system for reproductive isolation (Macnair and Christie, 1983). Secondly, it is possible that there are other genes in C10 or other Copperopolis plants that enhance the effectiveness of this gene, or can give tolerance at lower levels of copper, that have not been revealed by this crossing programme. There is no doubt, however, that the major part of the tolerance of $\mathrm{C} 10$ is due to a single major gene.

\section{Discussion}

In $\mathrm{C} 10$ there is a major gene for tolerance with some evidence of other genes of minor effect. Evidence that these results are typical of other individuals in the Copperopolis population comes from the analysis of two $5 \times 5$ F2 half diallels within the Copperopolis population (Macnair, 1976). These diallels both showed considerable additive and non-additive genetic variance for tolerance. Yet all of the 185 F2 individuals tested in these crosses were tolerant. Had there been any variation for the major gene present in $\mathrm{C} 10$, the segregation of some non-tolerants would have been expected. The significant genetic variance discovered in the diallels was presumably due to other modifying genes of lesser effect.

These results suggest that the evolution of metal tolerance, at least in Mimulus guttatus, follow the two step multigenic theory (see Turner, 1977). This model for adaptation suggests that the movement of a population from one adaptive peak to another involves initially the spread of a major gene, which, while not giving perfect adaptation, at least crosses the adaptive valley between the two peaks. Subsequently polygenic modification of this major gene can perfect the adaptation. This model contrasts with polygenic models of adaptation, in which progress from one peak to another involves gene frequency changes at a large number of loci of roughly equal effect.

What about heavy metal tolerance in other species? In general multigenic inheritance has been suggested for this character in most species studied (see e.g., Antonovics, Bradshaw and Turner, 1971; Gartside and McNeilly, 1974a, c). Yet the evidence is equivocal. One problem with genetical studies on tolerance, is the way in which tolerance is normally measured. The usual way of defining the tolerance in higher plants is to calculate a tolerance index (TI) in which rootgrowth in metal solution is compared with rootgrowth in control solution:

$$
\mathrm{TI}=\frac{\text { Rootgrowth in metal solution }}{\text { Rootgrowth in control solution }}
$$

(for a review of this technique and many of its drawbacks, see Wilkins, 1978). Generally, a concentration for the metal solution is chosen so as to allow all individuals, whether tolerant or not, to root. Then, apart from a few individuals which root better in the metal solution than in the control, 
all TIs lie between 0 and 1 . Yet the measurement of this TI is so inaccurate (because of variations in rooting) that error standard deviations of as much as 0.2 are not uncommon (Macnair, 1976; Wilkins, 1978). This means that one is almost bound to obtain a continuous distribution of phenotypes in almost any population or progeny, whether or not there is an underlying genetic segregation. In addition, any genes affecting rootlength per se, can also have an effect on the TI. So it is hardly surprising if crosses behave as if the character was polygenically controlled. Yet many of the published studies are consistent with models involving a relatively small number of genes of major effect (see Macnair, 1981). More research is needed before this issue can be resolved.

On the assumption of polygenic control of tolerance, several authors have suggested that the colonization of metal contaminated areas commences with the initial colonization by plants of low tolerance of areas of reduced toxicity ("nursery areas"), whence greater tolerance can evolve to enable the more toxic areas to be invaded. There is, however, little evidence that the evolution of metal tolerance does occur in this way. Tolerant individuals can be selected out from non-tolerant populations in Agrostis tenuis (Walley, Khan and Bradshaw, 1974; Gartside and McNeilly, 1974b), A. stolonifera (Wu, Bradshaw and Thurman, 1975) and Dactylis glomerata (Gartside and McNeilly, 1974b) by sowing normal seed onto mine soil. The only study into the dynamics of the natural colonization of a contaminated area is by Wu et al., (1975) who examined the colonization by $A$. stolonifera of several highly contaminated lawns at a copper refinery. The lawns were of different ages and different degrees of plant cover. Even the youngest lawns ( 8 years old) had some fully tolerant individuals, but the proportion of highly tolerant plants increased in lawns of increasing age. These results, coupled with the results from the selection experiments from normal seed, indicate that the initial colonization of toxic soils can take place by individuals directly from the non-tolerant populations that have the necessary tolerance gene or genes. Subsequently natural selection acts to increase the tolerance of the colonizers, through the spread of modifiers of the initial tolerance gene.

Apart from evolutionary considerations, the findings of a major gene for metal tolerance has important implications for the study of the physiological basis of metal tolerance. A number of separate physiological and biochemical processes have been implicated (see Thurman, 1981 for a review). If tolerance is polygenically controlled, then all of these mechanisms and others could be involved in producing the adaptation in any particular population. Both Woolhouse (1980) and Ernst (1976) have argued that a number of biochemical changes may be involved in the achievement of tolerance. The presence in $M$. guttatus of a single tolerance gene suggests that in this species, at least, there must be a single physiological or biochemical process that produces the initial tolerance necessary for the colonization of the toxic soil. Other biochemical and physiological differences may be found between mine plants and non-tolerant plants, but they would probably be manifestations of subsequent genetical changes improving the degree of adaptation, physiological "fine tuning". The basic tolerance mechanism must be produced by the product of the gene examined here. 
Acknowledgments. I thank Dr P. Christie, Dr P. M. Brakefield and Professor D. R. Davies for helpful comments on an earlier draft of this manuscript.

\section{REFERENCES}

ALLEN, W. R. AND SHEPPARD, P. M. 1971. Copper tolerance in some Californian populations of the monkey flower, Mimulus guttatus. Proc. R. Soc. B., 177, 177-196.

ANTONOVICS, J., BRADSHAW, A. D. AND TURNER, R. G. 1971. Heavy metal tolerance in plants. Adv. Ecol. Res., 7, 1-85.

BRÖKER, W. 1963. Genetisch-Physiologische Untersuchungen über die Zinkvertraeglichkeit von Silene inflata Sm. Flora. Jena., 153, 122-156.

ERNST, w. 1976. Physiological and Biochemical aspects of metal tolerance. The Effects of Air Pollutants in Plants (T. A. Mansfield, ed.), pp. 115-133. Cambridge University Press, Cambridge.

GARTSIDE, D. W. AND McNEILLY, T. 1974a. Genetic studies in heavy metal tolerant plants. I. Genetics of zinc tolerance in Anthoxanthum odoratum. Heredity, 32, 287-299.

GARTSIDE, D. W. AND McNEILLY, T. 1974b. The potential for evolution of heavy metal tolerance in plants. II. Copper tolerance in normal populations of different plant species. Heredity, 32, 335-349.

GARTSIDE, D. W. AND McNEILLY, T. 1974c. Genetic studies in heavy metal tolerant plants. II. Zinc tolerance in Agrostis tenuis. Heredity, 33, 303-308.

MACNAIR, M. R. 1976. The genetics of copper tolerance in Mimulus guttatus (Scrophulariaceae). Unpublished Ph.D. thesis, University of Liverpool.

MACNAIR, M. R. 1977. Major genes for copper tolerance in Mimulus guttatus. Nature, Lond., $268,428-430$.

MACNAIR, M. R. 1979. The genetics of copper tolerance in the yellow monkey flower, Mimulus guttatus. I. Crosses to non-tolerants. Genetics, Princeton, 91, 553-563.

MACNAIR, M. R. 1981. Tolerance of higher plants to toxic materials. Genetic consequences of man made change. (J. M. Bishop and L. M. Cook, eds.), pp. 177-208, Academic Press, London.

MACNAIR, M. R. AND CHRISTIE, P. 1983. Reproductive isolation as a pleiotropic effect of copper tolerance in Mimulus guttatus. Heredity, 50, 295-302.

THURMAN, D. A. 1981. Mechanism of metal tolerance in higher plants. Effects of heavy metal pollution on plants, Vol. II. N. W. Lepp, ed., pp. 239-249. Applied Science Publishers, London and New Jersey.

TURNER, J. R. G. 1977. Butterfly mimicry: the genetical evolution of an adaptation. Evolutionary Biology, 10, 163-206.

URQUHART, C. 1971. Genetics of lead tolerance in Festuca ovina. Heredity, 26, 19-33.

WALLEY, K. A., KHAN, M. S. AND BRADSHAW, A. D. 1974. The potential for evolution of heavy metal tolerance in plants I. Copper and zinc tolerance in Agrostis tenuis. Heredity, 32, 309-319.

WILKINS, D. A. 1960. The measurement and genetical analysis of lead tolerance in Festuca ovina. Rep. Scott. Pl. Breed. St., 85-98.

WILKINS, D. A. 1978. The measurement of tolerance to edaphic factors by means of root growth. New phytol., 80, 623-633.

wOOLHOUSE, H. W. 1980. Heavy metals in plants. Chemistry in Britain, 16, 72-76.

WU, L., BRADSHAW, A. D. AND THURMAN, D. A. 1975. The potential for evolution of heavy metal tolerance in plants. III. The rapid evolution of copper tolerance in Agrostis stolonifera. Heredity, 34, 165-187. 